\title{
The consequences of the Chernobyl accident: First results in the radioecology project of the French-German initiative
}

\author{
G. Deville-Cavelin, H. Biesold ${ }^{1}$, Ch. Brun-Yaba and V. Chabanyuk ${ }^{2}$ \\ Institute for Nuclear Safety and Protection (IPSN), Department for Environmental \\ Protection (DPRE), CE Cadarache, 13108 Saint-Paul-lez-Durance cedex, France \\ ${ }^{1}$ Gessellschaft für Anlagen- und Reaktorsicherheit (GRS) $\mathrm{mbH}$, \\ Wastes Management Division, Germany \\ ${ }^{2}$ Chornobyl Center for Nuclear Safety, Radioactive Wastes \& Radioecology, Ukraine
}

\begin{abstract}
The French-German Initiative for Chernobyl, implemented by IPSN and GRS, includes a Project on the Radioecological Consequences of the Accident. Different fields of radioecology and post-accidental aspects had been chosen, such as radionuclides transfers to plants, to animals, by surface run-off, in the aquatic environment and in the urban environment, wastes management and countermeasures. Data from Belarus, Russia and Ukraine, have been collected, verified and organized. This constitutes a tool for development and validation of operational, assessment and explicative models. In the different part of ecosystems, the radionuclides transfers have been quantified and the main parameters influencing identified. For wastes, unified categorizations for the three countries have been adopted for wastes and for disposals. The operational database built allows the management of the wastes disposal sites. Countermeasures used after the accident for urban areas, natural and agricultural environment, have been described and classified. A methodology for evaluating their effectiveness has been developed. For linking the different data, maps of initial and present contamination by ${ }^{137} \mathrm{Cs}$ and ${ }^{90} \mathrm{Sr}$ have been drawn up and relevant environmental non radioactive data have been collected with all the others, structured in an unique database REDAC and georeferenced using a Geographical Information System.
\end{abstract}

\section{Frame and history of the Radioecology Project}

In April 1996 in Vienna, during the IAEA conference for the tenth anniversary of the Chernobyl accident the French and German Ministers of Environment decided to start actions for evaluating consequences of the accident and help the three concerned countries, Ukraine, Belarus and Russia to overcome those consequences.

This French-German Initiative (FGI) for Chernobyl was materialised by an agreement signed by the "Institut de Protection et de Sûreté Nucléaire" (IPSN - France) and the Gesellschaft für Anlagenund Reaktorsicherheit (GRS - Germany) with the ukrainian authorities ('Chornobyl Centre).

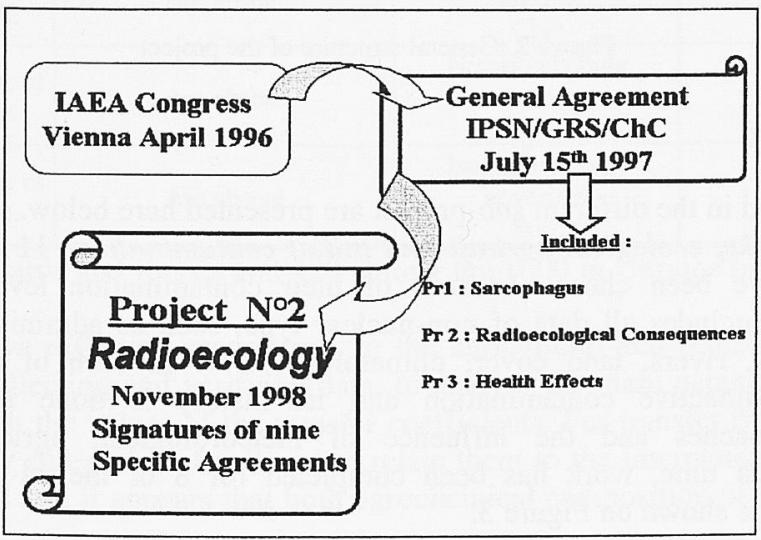

Figure 1: history of the project 
FGI includes three projects, one for studying the safety of the sarcophagus, the second for evaluating the radioecological consequences of the accident and the third for the health effects of the disaster. The Project $n^{\circ} 2$, dedicated to Radioecology studies began on the end of 1998 by the signature of nine specific agreements each agreement corresponding to a specific sub-project in the chosen field:

a. transfer of radionuclides ( $R N)$ in the different parts of the ecosystems, from soils to plants and from plants to animals, by surface runoff, in the aquatic environment and the urban environment.

b. studies on the wastes disposal

c. studies on countermeasures and their effectiveness in agricultural, natural and urban areas

\section{Purposes and structure}

Purposes of the project are of four types :

a. In Belarus, Ukraine and Russia, collecting, securing and validating existing radioecological data for building a database called REDAC (RadioEcological Database After Chernobyl),

b. Using collected data for validation, adaptation and development of radioecological models,

c. Giving elements for building tools to be used by decision-makers in post accidental management,

d. Informing about consequences of the accident for the environment.

The following structure (Figure 2) has been adopted, centred on the common data to be integrated using a Geographical Information System (GIS).

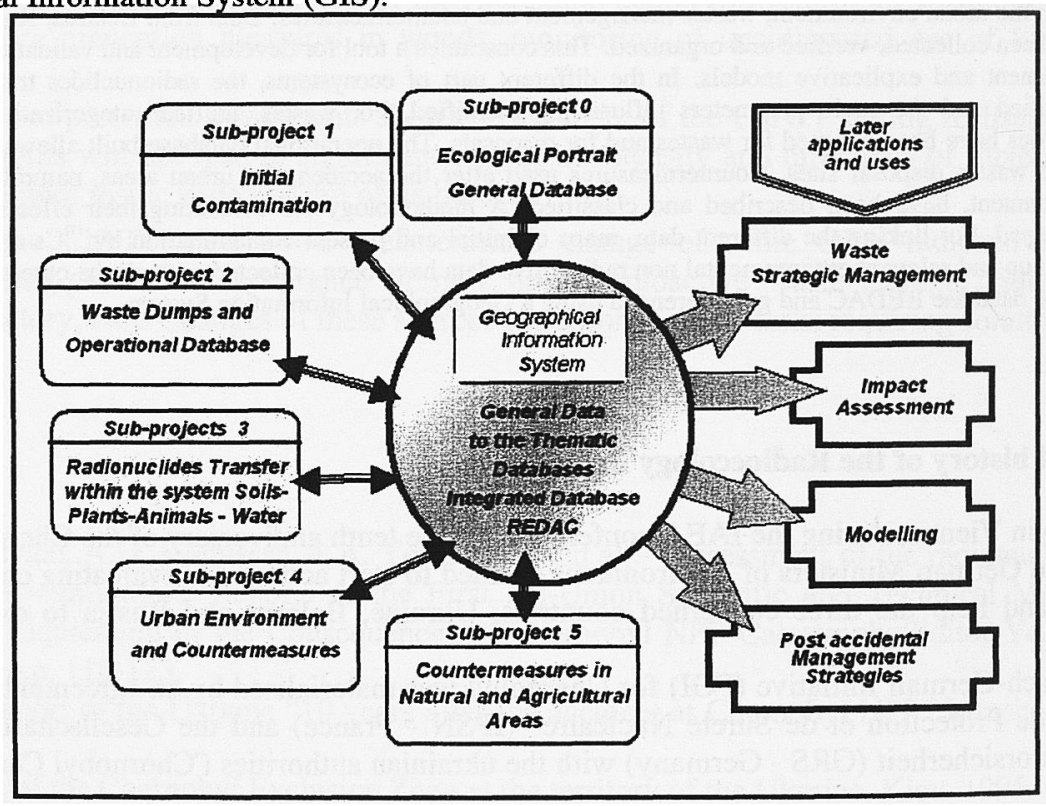

Figure 2 :General structure of the project

\section{Main results obtained}

The main results obtained in the different sub-project are presented here below.

For the general tasks, ecological portrait and initial contamination, 11 oblasts distributed in the three countries have been chosen because of their contamination levels. In each oblast, the ecological portrait includes all data of non-nuclear type, such as administrative data, population, roads and railways, rivers, land cover, climatology, ... . In each of the studied territories a compilation of radioactive contamination and its history is done then analysed including geostatistical approaches and the influence of meteorological, agricultural and orographic peculiarities. At this time, work has been completed for 8 of the 11 oblasts. An example of contamination map is shown on Figure 3. 


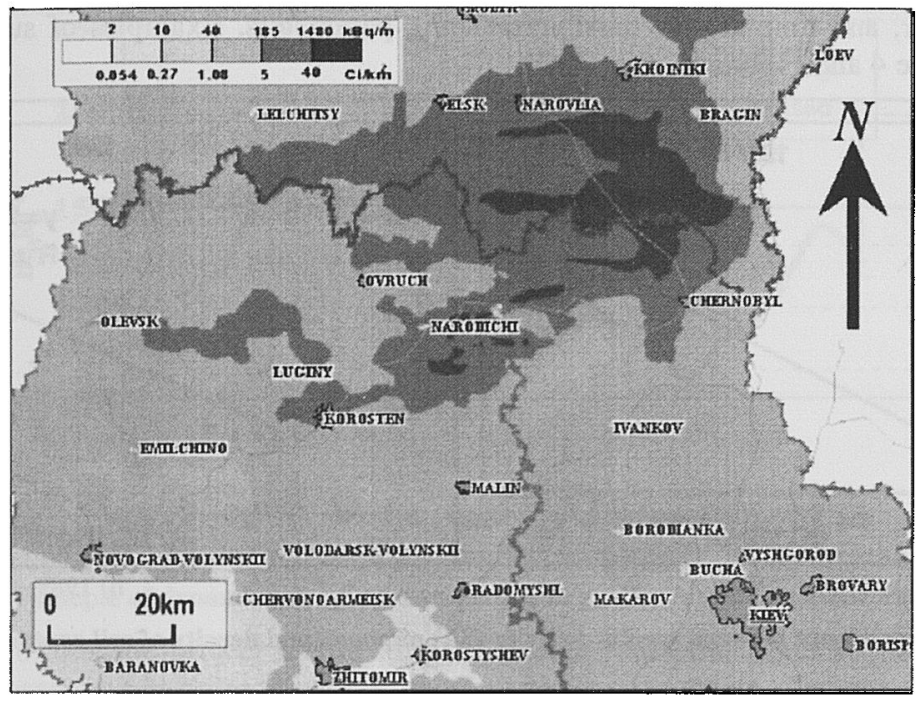

Figure 3: Map of contamination by ${ }^{137} \mathrm{Cs}$ (part: "western trace")

For wastes, the first goals are to locate all radioactive disposals in the studied zones, to characterize them and their contents in term of nature and quantity of radioactivity. About 1000 disposals are to be studied in Ukraine, 88 in Belarus and 19 in Russia.

The second part of the work is to evaluate consequences of wastes disposals on the environment and to choose actions, treatments and strategies to minimize theme with an optimisation of related expenses.

The first step has been to define categories of wastes, according to*• and • activity and taking into account the national regulatory for radioactive wastes. In the same manner, disposals have been categorized following Table 1 .

Table 1: Categorisation of disposals

\begin{tabular}{|c|c|c|c|c|}
\hline Category & $\begin{array}{c}\text { Type of } \\
\text { disposal site } \\
\end{array}$ & $\begin{array}{c}\text { Basement and wall. } \\
\text { Material }\end{array}$ & $\begin{array}{l}\text { Isolation. } \\
\text { Material } \\
\end{array}$ & $\begin{array}{c}\text { Wastes placement mode } \\
\text { and package }\end{array}$ \\
\hline A & Surface & $\begin{array}{l}\text { Basement and wall. } \\
\text { Concrete, reinforced } \\
\text { concrete }\end{array}$ & $\begin{array}{l}\text { Isolation is only } \\
\text { covering. } \\
\text { Concrete, clay }\end{array}$ & $\begin{array}{c}\text { Capacities of reinforced concrete } \\
\text { Neither packaged nor non- } \\
\text { packaged. }\end{array}$ \\
\hline B & $\begin{array}{l}\text { Near-surface; of } \\
\text { trench type. }\end{array}$ & $\begin{array}{l}\text { Basement and wall. } \\
\text { Concrete, reinforced } \\
\text { concrete }\end{array}$ & $\begin{array}{c}\text { Isolation is covering and } \\
\text { littering. } \\
\text { Clay }\end{array}$ & $\begin{array}{l}\text { Neither packaged nor non- } \\
\text { packaged. }\end{array}$ \\
\hline $\mathbf{C}$ & $\begin{array}{c}\text { Near-surface; of } \\
\text { trench type. }\end{array}$ & Are absent & $\begin{array}{c}\text { Isolation is covering and } \\
\text { littering. } \\
\text { Clay }\end{array}$ & Non-packaged \\
\hline D & $\begin{array}{c}\text { Near-surface; of } \\
\text { trench type. }\end{array}$ & Are absent & $\begin{array}{l}\text { Isolation is only } \\
\text { covering. } \\
\text { Soil. }\end{array}$ & Non-packaged \\
\hline $\mathrm{E}$ & $\begin{array}{c}\text { Near-surface; of } \\
\text { clamp type. }\end{array}$ & Are absent & $\begin{array}{l}\text { Isolation is only } \\
\text { covering. } \\
\text { Soil. }\end{array}$ & Non-packaged \\
\hline
\end{tabular}

All disposals in Belarus and Russia and 500 among the 1000 in Ukraine have been now located and characterized.

For transfers in the different ecosystems, in the agricultural and semi-natural environments, the purpose is, after collecting and verifying data, to analyse the main parameiers influencing transfer, for example through the values of the transfer coefficients. For transfer from soil to plants, the first task was to identify categories of soil and to relate them to the international system FAO. Transfer has been quantified and it appears that both agrochemical composition of soil, especially content of 
organic matter, and time are the most influencing parameters. Examples of such dependences are given in Figure 4 and Figure 5.

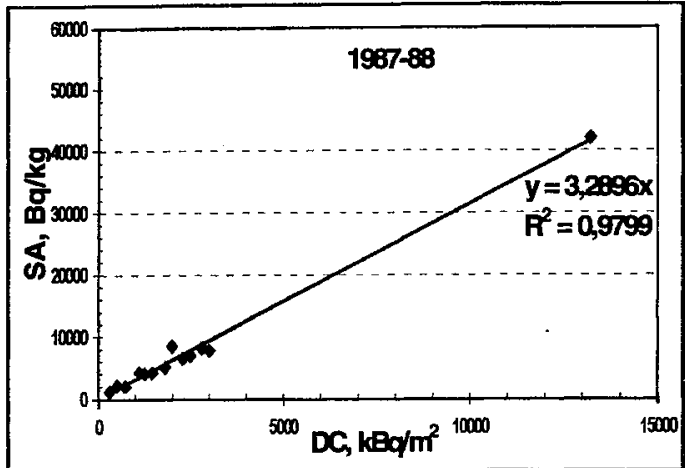

a) $1987-1988$

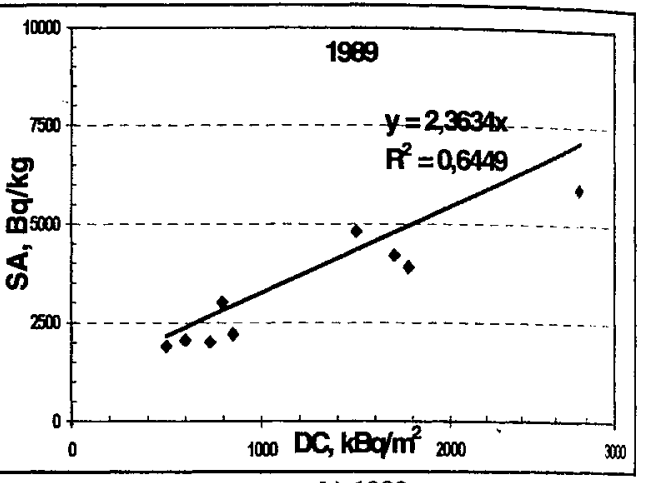

b) 1989

Figure 4 : Dependence between specific activity (SA) of plants and density of soil contamination (DC)

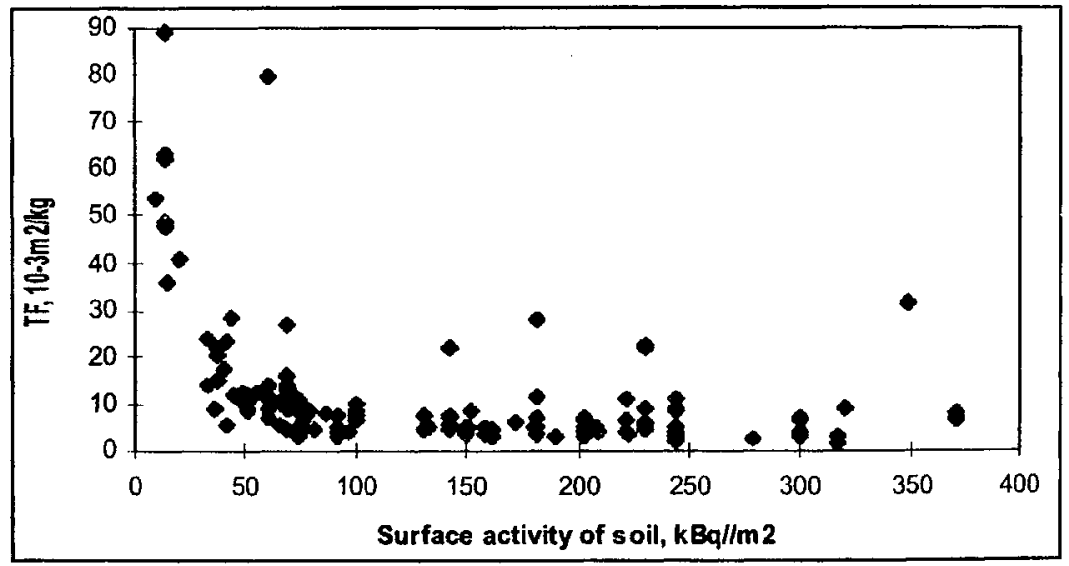

Figure 5 : Dependence between transfer factor (TF) to hay and surface activity of soil (SA)

For transfers by surface runoff, all data from monitoring of the contaminated zone has been collected, with precise description of elementary watersheds. In addition description and data from runoff plot experiments performed just after the accident in the exclusion zone have been also collected. The first phase of the work includes also an overview of methods for modeling radionuclides transfer [ 1 ] to be compared with the experimental results.

In the aquatic environment, the goal is, by using monitoring data in the water bodies of the contaminated zone, to validate a model (TRANSAQUA) previously developed by IPSN. For this purpose, one water body has been chosen in each of the three countries, the Dniepr Reservoir in Ukraine, the lake Svyatskoye in Belarus and the lake Khozanovskoye in Russia. For each water body, available biotic and abiotic parameters have been adapted to be used in TRANSAQUA. Then, some simulations have been performed with the model using the real conditions for different species of fish. Parameters have been adapted in order to better the fit between observed values in the water bodies and model assessments. An example of comparison is shown in Figure 6.

For the urban environment the task is double. First to do an overview of the different existing methods for assessing radionuclides transfers in the medium. The code to be tested is the Danish code developed in Risøe Its result shall be compared to the observed data in the settlements. 


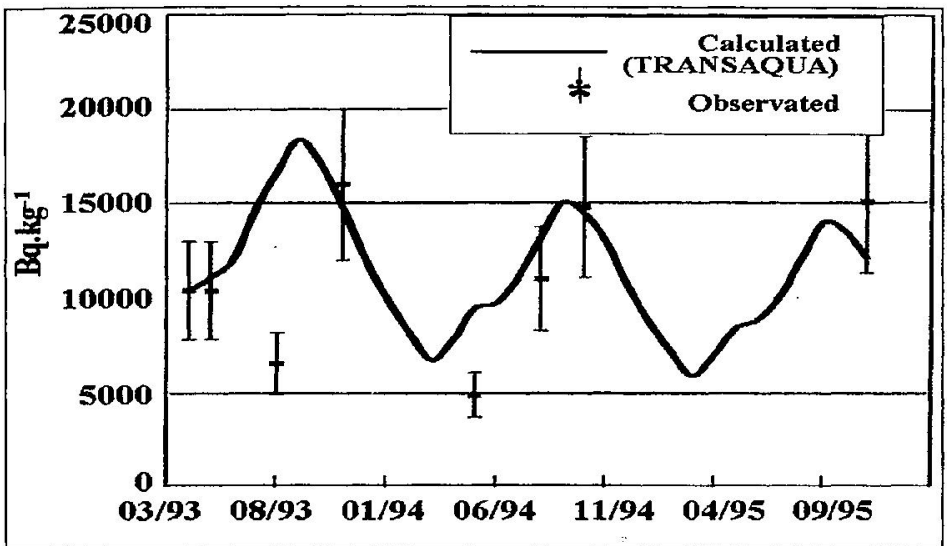

Figure 6 :Example of dynamics of ${ }^{137}$ Cs accumulation in goldfish - Lake Koshanovskoe (Russia)

Then the goal of this sub-project is collecting all data on countermeasures applied in settlements and cities after the accident in order to classify them and to evaluate their efficiency. Georeferenced map of radiological data are being built.

Countermeasures in agricultural and natural environment are the subject of the last sub-project. Here it is question of collecting data about countermeasures applied in order to evaluate their effectiveness. First a classification of the different countermeasures has been established according to the field of implementation (agricultural, semi-natural and natural environments, hydrological systems) and the means applied (organisational, restrictive, technical or technological).

On these bases, a data base, to be included in REDAC, is built and filled. This allows the comparison of efficiency between the different methods as shown in [ 2 ] illustrated by Figure 7.

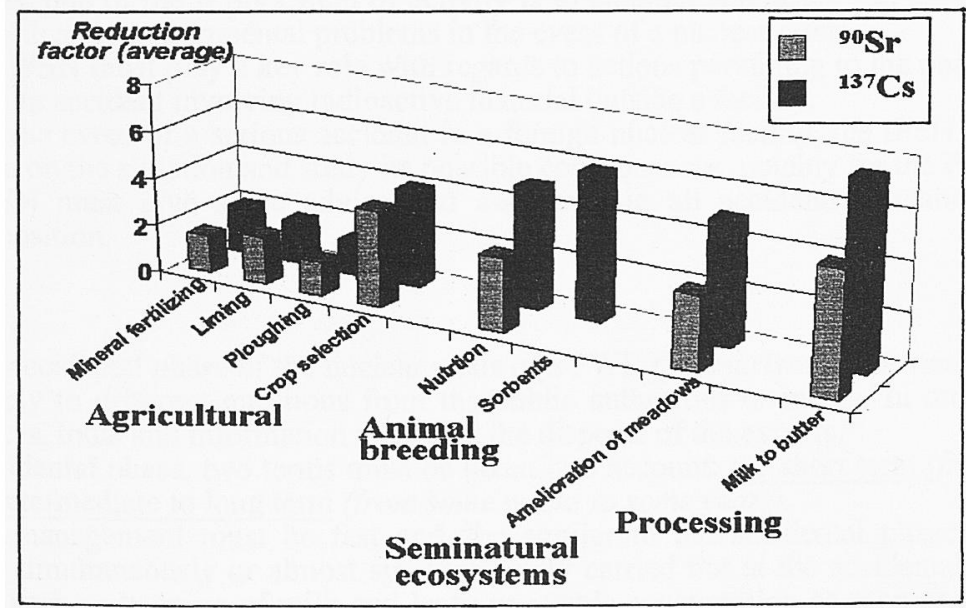

Figure 7 : Effectiveness of countermeasures in agricultural and semi-natural environment

The different databases shall be now completed and used for some comparisons between field data and modelling results. Then, based on the methods (GIS) used in the general sub-projects, a "soft" integration shall be performed between the nine sub-projects in order to harmonise data and methods. The whole project Radioecology should be completed in the middle of 2002 , including the final version of the integrated database REDAC. 


\section{Acknowledgments}

The authors are grateful to the sub-projects managers:

L. TABACHNY

I. LINGE

Pr E. SOBOTOVITCH

Pr B. PRISTER

Pr R. ALEXAKHIN

Dr A. KONOPLEV

Dr O. VOITSEKHOVITCH

Pr I. BOGDEVITCH

Dr G SOKOLIK

\section{Ministry of Emergency Situations of Ukraine}

Nuclear Safety Institute IBRAE - Russia

State Scientific Centre for Ecology and Radiochemistry - Ukraine

Ukrainian Institute for Agricultural Radiology

Russian Institute of Agricultural Radiology and Agroecology SPA "TYPHOON" Russia

and all national co-ordinators of the nine sub-projects of FGI Radioecology project, which work allowed this presentation.

\section{References}

[ 1 ] Konoplev A. V., Radionuclides transfer by surface runoff : modelling and parametrisation (IPSN/GRS, report FGI 00/Pr2/01, 2000)

[ 2 ] Deville-Cavelin G. and al., "Countermeasures in agriculture : assessment of efficiency", Fifteen years after Chernobyl - Lessons learned, Kiev - Ukraine April $18^{\text {th }}-20^{\text {th }} 2001$. 